\title{
EFFECT OF VEGETABLE OIL QUENCHANTS ON THE PROPERTIES OF ALUMINUM DURING SOLUTION HEAT TREATMENT
}

\author{
J.K. Odusote ${ }^{*}$, A.S. Adekunle ${ }^{2}$ and A.B. Rabiu ${ }^{2}$ \\ ${ }^{1}$ Department of Materials and Metallurgical Engineering, \\ University of Ilorin, Ilorin, Nigeria \\ ${ }^{2}$ Department of Mechanical Engineering, University of Ilorin, Ilorin, Nigeria \\ *Email: jamiukolawole@gmail.com, \\ Phone: +2347038848812 ; Fax: +23431221937
}

\begin{abstract}
Proper selection of appropriate quenching media can result in improved mechanical properties of pure commercial aluminum after solution heat treatment. This paper presents the effect of heat extraction by groundnut, melon, palm kernel, shea butter and palm oils on the mechanical properties of various samples of pure commercial aluminum heat treated at $200{ }^{\circ} \mathrm{C}, 250{ }^{\circ} \mathrm{C}, 300{ }^{\circ} \mathrm{C}$ and $350^{\circ} \mathrm{C}$. A muffle furnace equipped with a digital thermometer and a thermocouple was used for the solution heat treatment. Tensile strength and hardness tests were carried out using an Instron Universal Tester and Vickers hardness methods, respectively. The results showed that palm kernel oil cools faster at $200{ }^{\circ} \mathrm{C}$ and $250{ }^{\circ} \mathrm{C}$, while palm oil and shea butter oil quench faster at $300{ }^{\circ} \mathrm{C}$ and $350{ }^{\circ} \mathrm{C}$, respectively. Solution heat treatment with palm kernel oil offered the highest percentage elongation at $200{ }^{\circ} \mathrm{C}$, while at $350{ }^{\circ} \mathrm{C}$ shea butter oil gave the best percentage elongation. The best among the bio-quenching oils in providing good ductility is shea butter oil at $200{ }^{\circ} \mathrm{C}$, while at $300{ }^{\circ} \mathrm{C}$ and $350{ }^{\circ} \mathrm{C}$ groundnut oil gives the best result. Highest hardness values were obtained from samples quenched in melon oil between $200{ }^{\circ} \mathrm{C}$ and $300{ }^{\circ} \mathrm{C}$. However, these values decreased with increased heating temperature, probably due to the density and viscosity variation with temperature rise. Similar observations were made on other samples quenched in other bio-quenchant oils used in this experiment. This study shows that locally available vegetable oils have promising potential to serve as a possible replacement for nonbiodegradable mineral oils in many applications.
\end{abstract}

Keywords: Aluminum; heat extraction rate; vegetable oils; solution treatment; mechanical properties.

\section{INTRODUCTION}

Aluminum is widely used in the electrical, chemical, food packaging, petrochemical and construction industries on account of its excellent corrosion resistance, high thermal and electrical conductivities and good formability [1]. One major drawback to the use of pure commercial aluminum is its low strength [1]. It has been established that the mechanical properties of metals and alloys can be effectively improved through alloying and heat treatment [2]. However, the choice of an effective quenching medium after heat treatment is critical in ensuring the achievement of the desired mechanical properties [3]. The most common quenching medium for metals and alloys is mineral oil, which possesses excellent cooling capacity [4]. However, it is relatively expensive, 
toxic and non-biodegradable. A considerable number of studies have focused on the possibility of reducing or replacing mineral oil with less expensive water-based or polymer-based quenching media [5]. The cooling capacity of aqueous solutions of different substances was examined in order to determine their suitability as quenching media, and it was observed that aqueous 6-7\% monosulfite liquor (MSL) with $1 \%$ phenol could serve as a possible replacement for mineral oils [4]. Protsidium et al. [6] studied the quenching capacity of spent and regenerated minerals oils, and observed that the addition of $0.3 \%$ antioxidant lonol to regenerated oils improved their quenching capacity. The effectiveness of polymer-based quenching medium, UZSP-1, was examined, and it was found that UZSP-1 of varying concentrations was effective as a quenching medium for only low-carbon ball-bearing steels [7], but not well suited to high-carbon ball-bearing steels.

In recent studies, the suitability of some locally available biodegradable oils as quenching media during heat treatment of plain carbon steel [8-10] and as cutting lubricants during machining operations $[9,11]$ has been reported. The present study was undertaken with the objective of replacing mineral oils with local biodegradable oils, which are more readily available, relatively cheaper and more environmentally friendly. These oils also have many other good natural properties, which make them attractive as lubricants and in other applications [12]. Thus, the aim of this work is to determine the effect of using some locally available vegetable oils as quenching media on the mechanical properties of $\mathrm{Al}$ after solution heat treatment.

\section{EXPERIMENTAL SET-UP}

\section{Experimental Procedure}

The workpiece material is pure commercial aluminum, obtained from a local aluminum smelting company based in Lagos, with the following composition: $99.83 \% \mathrm{Al}, 0.04 \%$ $\mathrm{Zn}, 0.07 \% \mathrm{Si}, 0.02 \% \mathrm{Mn}, 0.02 \% \mathrm{P}$ and the rest traces of $\mathrm{Ni}$ and $\mathrm{S}$. The as-received sample was cut into experimental workpieces prior to solution heat treatment. The treatment was performed at $200{ }^{\circ} \mathrm{C}, 250{ }^{\circ} \mathrm{C}, 300^{\circ} \mathrm{C}$ and $350{ }^{\circ} \mathrm{C}$, using a muffle furnace. After heat treatment, the samples were soaked for 60 minutes inside the furnace and then quickly transferred into a quenching bath equipped with a digital thermometer and thermocouple. The quenching bath was filled separately with $50 \mathrm{~cm}^{3}$ of groundnut oil, melon oil, palm oil, palm kernel oil and shea butter oil as the quenchants. The heat losses by the heat-treated pure commercial aluminum were recorded by the digital thermocouple at various time intervals from $30 \mathrm{~s}$ to $300 \mathrm{~s}$. After quenching, specimens of approximately $10 \mathrm{~mm}$ long and $9 \mathrm{~mm}$ in diameter were cut from the quenched samples. The specimens were ground and polished with 400 -grit SiC paper and $1 \mu \mathrm{m}$ diamond paste finish, respectively. After polishing, the specimens were cleaned ultrasonically in acetone, followed by alcohol, and immediately dried before hardness and other mechanical tests.

\section{Tensile Testing}

Tensile tests were carried out on the quenched specimens using an Instron Universal Tester and the dimensions of the test specimens were according to British Standards (BS) standard. Each of the specimens was loaded till fractured, and the fracture load for each sample was recorded as well as the diameter at the point of fracture and the final 
gauge length. The initial diameter and initial gauge length for each sample was noted before the application of the uniaxial load. The percentage elongation of each test sample was determined, as well as the tensile strength.

\section{Hardness Test}

The Vickers hardness method was used to determine the hardness of the quenched samples. Each of the test specimens were prepared metallographically after different heating and quenching regimes, and then mounted on the anvil. The specimens were brought into contact with the pyramid indenter and allowed to rest for a dwell time of 10 $\mathrm{s}$ under an applied load of $490.3 \mathrm{mN}$ at three different points and the depth of penetration of the indenter was noted. The hardness of the specimens was indicated by the penetration of the indenter into the test specimens, and displayed by the machine. Average values were recorded after repeating the test for each of the test specimens.

\section{RESULTS AND DISCUSSION}

\section{Cooling Rate}

Figure 1 shows the rate of heat extraction by each of the quenching media, namely groundnut, melon, palm, palm kernel and shea butter oils, from the heat-treated pure aluminum samples after heating at $200{ }^{\circ} \mathrm{C}, 250{ }^{\circ} \mathrm{C}, 300{ }^{\circ} \mathrm{C}$ and $350{ }^{\circ} \mathrm{C}$, respectively. The figure reveals that at $200{ }^{\circ} \mathrm{C}$, palm kernel oil extracted heat to an elevated temperature of $31.9{ }^{\circ} \mathrm{C}$ at $160 \mathrm{~s}$, while groundnut, melon, shea butter and palm oils extracted heat to $31.6^{\circ} \mathrm{C}$ at $185 \mathrm{~s}, 31.8^{\circ} \mathrm{C}$ at $245 \mathrm{~s}, 31.8^{\circ} \mathrm{C}$ at $205 \mathrm{~s}$, and $31.6{ }^{\circ} \mathrm{C}$ at $265 \mathrm{~s}$, respectively. This indicates that palm kernel oil extracted heat and reached equilibrium with the samples faster than the other oils at this heating temperature, while the least heat was extracted by palm oil at this heating temperature. This result shows that palm kernel oil has the best cooling capacity as compared with the other vegetable oils at $200{ }^{\circ} \mathrm{C}$, since cooling capacity reflects the ability of a fluid to remove heat from the heated material during the quenching process [2]. Palm kernel oil has been reported to have very low linoleic $(\mathrm{C} 18: 2)$ value, which indicates a high rate of heat extraction according to Adekunle et al. [8]. In addition, the observation may also be dependent on the viscosity as well as the percentage composition of the fatty acids in the various vegetable oils [8]. However, the temperature of each of the quenchants remained constant after reaching their elevated temperatures during the quenching process, indicating relative stability in the rate of heat extraction at that temperature.

As shown in Figure 1, the temperatures of both palm kernel and melon oils were raised to $32.5{ }^{\circ} \mathrm{C}$ from $30.8{ }^{\circ} \mathrm{C}$ at $175 \mathrm{~s}$ and $250 \mathrm{~s}$, respectively, during the quenching of the aluminum samples heated to $250{ }^{\circ} \mathrm{C}$, while those of groundnut, shea butter and palm oils were raised to $32.4{ }^{\circ} \mathrm{C}$ at $165 \mathrm{~s}, 32.2^{\circ} \mathrm{C}$ at $145 \mathrm{~s}$ and $31.7^{\circ} \mathrm{C}$ at $280 \mathrm{~s}$, respectively. This shows that palm kernel oil extracted faster than the other oils, while palm oil extracted the least heat at $250{ }^{\circ} \mathrm{C}$. However, at $300{ }^{\circ} \mathrm{C}$ palm oil cools the heated aluminum faster as more heat was extracted, while at $350{ }^{\circ} \mathrm{C}$ shea butter oil cooled the heated aluminum faster compared with the other oils. Vegetable oils have been reported to have good lubricity, wetting ability and cooling behavior [9]. The cooling behavior of edible and non-edible vegetable oils has been found to be strongly dependent on the viscosity of the quench oils [8]. 


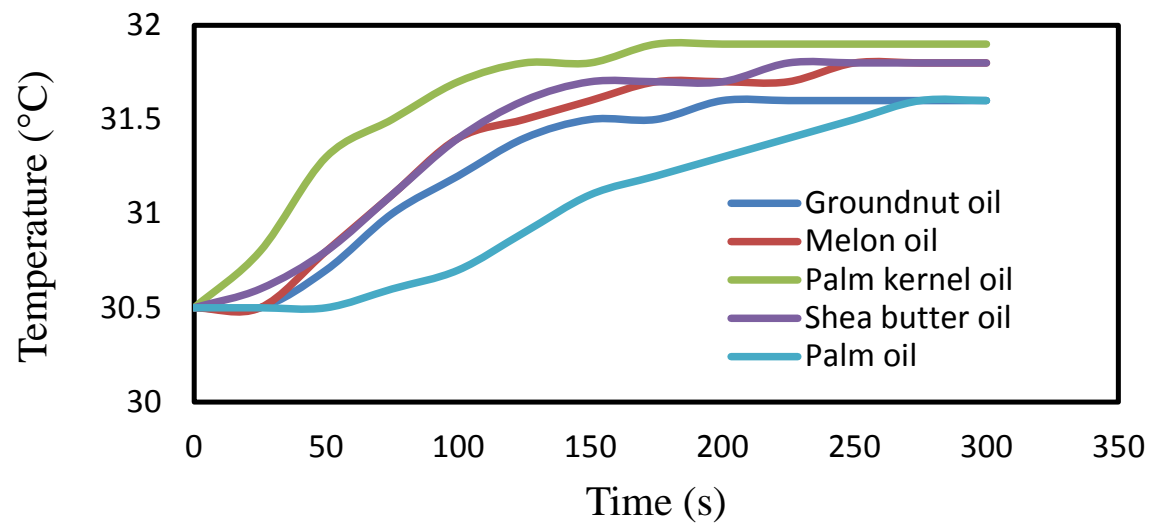

(a)

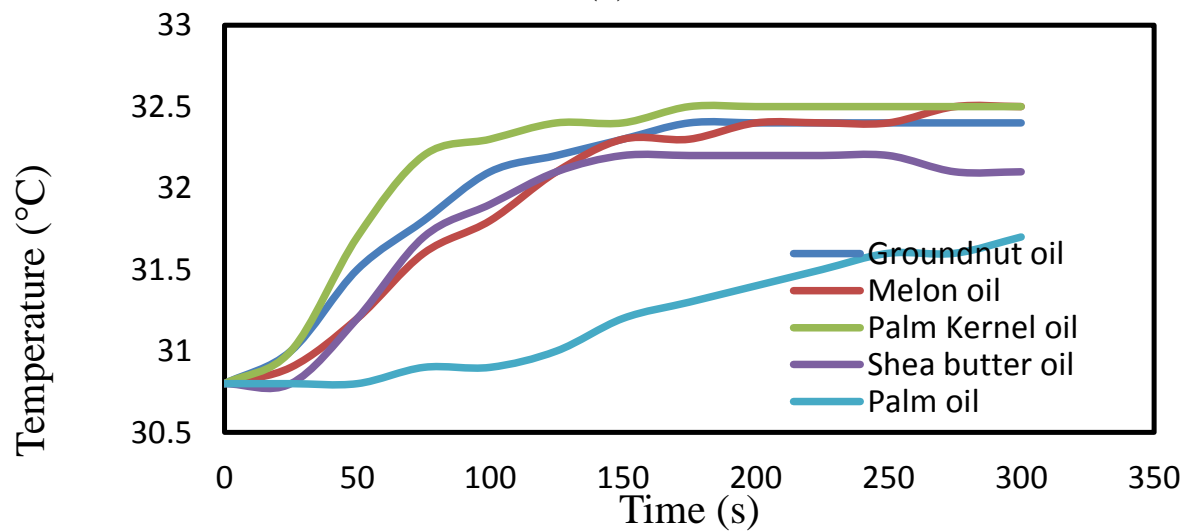

(b)

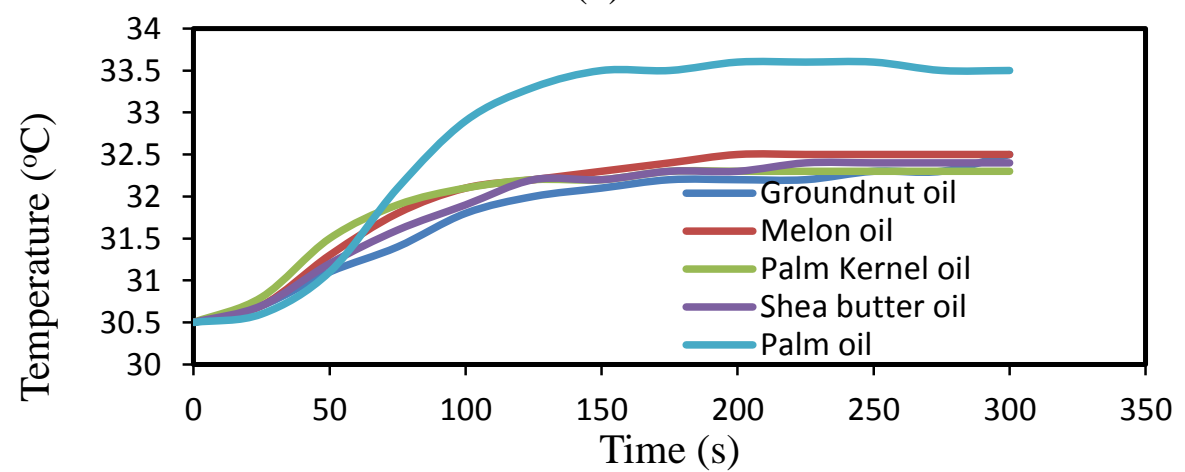

(c)

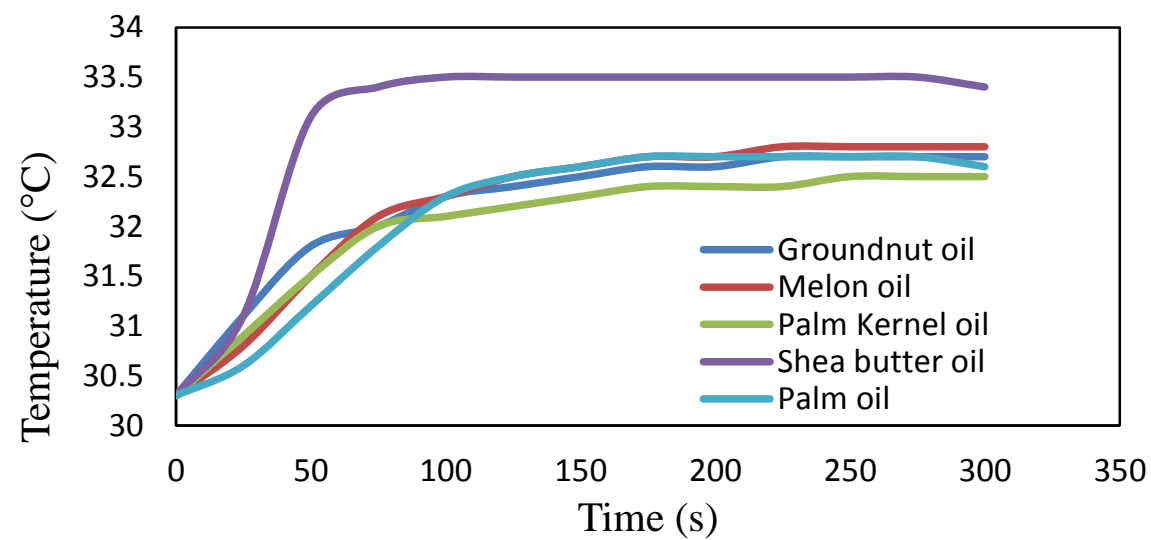

(d)

Figure 1. The rate of heat extraction of different bio-quenching oils at different temperatures (a) $200{ }^{\circ} \mathrm{C}$ (b) $250{ }^{\circ} \mathrm{C}$ (c) $300{ }^{\circ} \mathrm{C}$ (d) $350{ }^{\circ} \mathrm{C}$. 
Adekunle et al. [8] studied the cooling rate of steel samples heated up to $850{ }^{\circ} \mathrm{C}$ in an electric furnace and quenched in different bio-quenching oils. The rate of heat extraction by groundnut oil was found to be the highest, followed by melon oil, shea butter oil, palm kernel oil and the least was palm oil. In the current study, the cooling behavior of the vegetable oils was also found to be dependent on the peak temperature of the heated samples prior to quenching, indicating the possible effect of the heating temperature on the viscosity properties and thus cooling rate of the vegetable oils. However, the observations in the current study are not in agreement with the results of Adekunle et al. [8] possibly due to the different properties of the metals involved and the lower heating temperatures of the current samples.

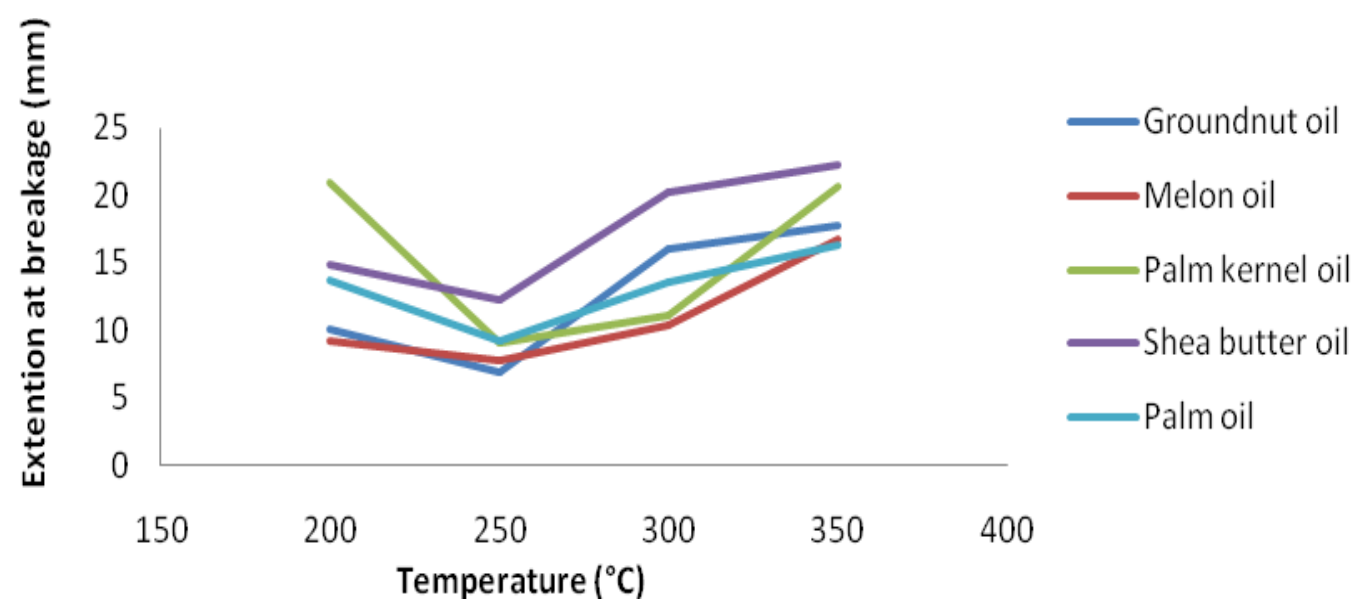

Figure 2. Percentage elongation of pure commercial aluminum in different bioquenching oils at different heating temperatures.

\section{Percentage Elongation of Quenched Samples}

Figure 2 shows the percentage elongation of the investigated samples after quenching in various bio-quenching oils at different exposure temperatures. Comparing the value of elongation of the quenched samples at different heating temperatures with the asreceived sample of $14.09 \mathrm{~mm}$, it was evident that, in most cases, the percentage elongation of the quenched samples increased with increasing heating temperature, as shown in Figure 2. This indicates possible improvement in the ductility of the quenched samples at higher heating temperatures. This observation may be due to the faster cooling rate of the samples at lower heating temperatures, which will have a negative effect on the sample elongation and thus ductility [13]. The least elongation value of $6.92 \mathrm{~mm}$ was obtained after quenching in groundnut oil at $250{ }^{\circ} \mathrm{C}$, while shea butter oil produced samples with the highest ductility at $350{ }^{\circ} \mathrm{C}$. All the samples heated at $200{ }^{\circ} \mathrm{C}$ and $250{ }^{\circ} \mathrm{C}$ and quenched in the various oils are brittle, except those quenched in shea butter oil at $200{ }^{\circ} \mathrm{C}$, which are slightly ductile possibly due to the slow rate of heat extraction at that temperature. Samples heated at $300{ }^{\circ} \mathrm{C}$ and quenched in groundnut and shea butter oils are also ductile, while those quenched in other oils are brittle. However, at $350{ }^{\circ} \mathrm{C}$, all the quenched samples exhibited ductility, with the highest elongation of $22.25 \mathrm{~mm}$ displayed by those quenched in shea butter oil. Samples cooled from $350{ }^{\circ} \mathrm{C}$ are more likely to experience slow cooling compared with those quenched from lower temperatures. Slow cooling of the heat-treated metal samples usually resulted in the 
formation of fine-grain structures, which are more ductile and thus exhibit better ductility [14].

\section{Tensile Strength of the Quenched Samples}

The tensile strength of the as-received commercial Al sample is $60.04 \mathrm{MPa}$, which is higher than that obtained from the quenched samples at some of the heating temperatures (Figure 3). At $200^{\circ} \mathrm{C}$, samples quenched in groundnut and melon oils displayed lower tensile strength compared with that of the as-received sample, while shea butter oil exhibited the highest tensile strength value of $67.38 \mathrm{MPa}$. This value is higher than the $65.62 \mathrm{MPa}$ and $61.21 \mathrm{MPa}$ of palm kernel and palm oils, respectively. All the curves have similar trends at this temperature except palm oil with a fluctuating curve possibly due to its high palmitic (C16:0) value of above $20 \%$ [8]. At $250{ }^{\circ} \mathrm{C}$, all the quenched samples gave lower tensile strength values compared with that of the asreceived sample, with the sample quenched in groundnut oil showing the lowest tensile strength value. However, at $300{ }^{\circ} \mathrm{C}$ and $350{ }^{\circ} \mathrm{C}$, heat-treated samples quenched in groundnut oil displayed the highest tensile strength value, followed by those quenched in shea butter oil, with the least value being obtained from samples quenched in melon oil at $300^{\circ} \mathrm{C}$, and in palm oil at $350^{\circ} \mathrm{C}$. Thus, quenching in groundnut oil after heating at $350^{\circ} \mathrm{C}$, resulted in the sample with the best tensile strength. The tensile strength of quenched samples has been reported to be influenced by the heat treatment temperature and the quenching operations [10]. Thus, the tensile strength of the samples at different heating temperatures is not likely to be the same as that observed in the current study. In addition, the behavior of the vegetable oils with regard to their resistance to the motion of vapor bubbles during the nucleate boiling stage in order to reduce the supply of cold liquid to the heated surface is influenced by their viscosity [8]. Higher viscosity bioquenching oils offer greater resistance compared with those with low viscosity and thus they possess lower heat transfer coefficients [8]. Hence, the performance of each of the bio-quenching oils in the current study may be largely dependent on their viscosity, which is determined by the amount of fatty acids present in them, as reported by Adekunle et al. [8]. Groundnut oils have lower viscosity and a higher heat transfer coefficient [8], and thus remove heat faster from the heated samples, resulting in the formation of fine-grain structures with better tensile strength [14].

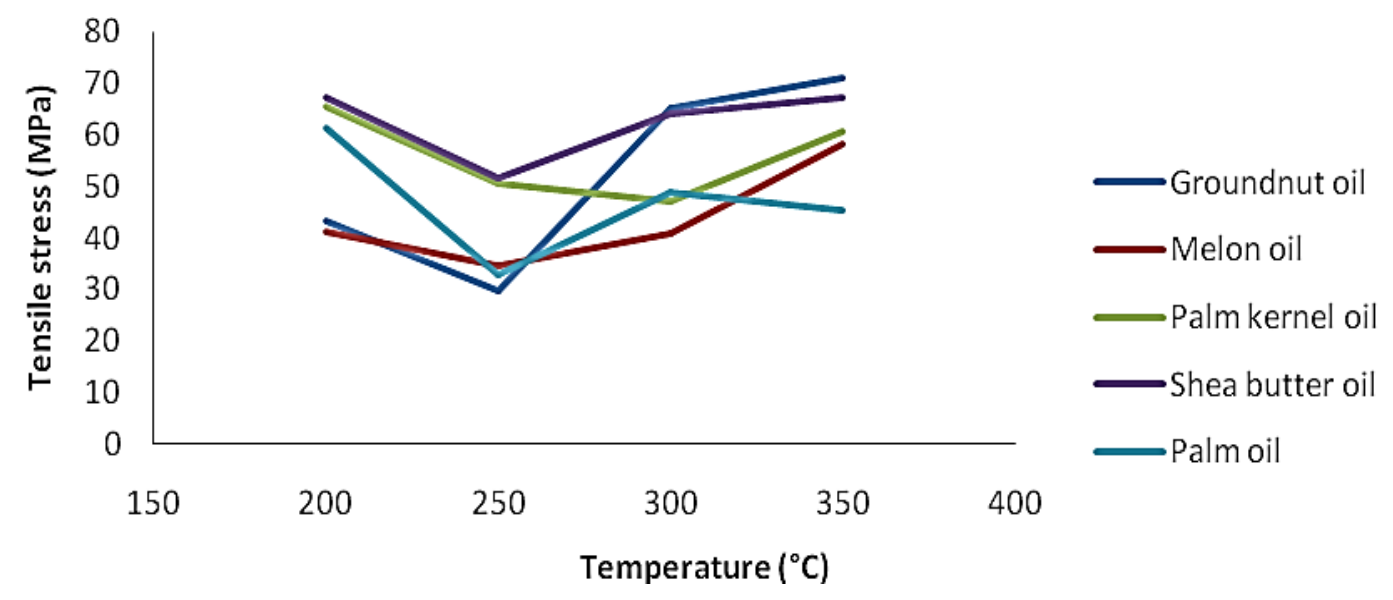

Figure 3. Tensile strength of pure commercial aluminum in different bio-quenching oils at different heating temperatures. 


\section{Variation of the Hardness of Quenched Samples}

The highest Vickers hardness value of the samples quenched in the various quenching oils was obtained at $200{ }^{\circ} \mathrm{C}$, with the peak value from the sample quenched in melon oil, as shown in Figure 4 . However, at $250{ }^{\circ} \mathrm{C}$, the hardness values of all the quenched samples decreased, with those quenched in melon, palm kernel and shea butter oils being lower than that of the as-received sample, which is $30.9 \mathrm{Hv}$. The hardness values of all the samples increased at $300{ }^{\circ} \mathrm{C}$ above that of the as-received, but later decreased when quenched after heating up to $350{ }^{\circ} \mathrm{C}$, except that of the sample quenched in melon oil. This indicates that the best heating temperature to obtain the highest hardness value will be $200^{\circ} \mathrm{C}$, with melon oil as the quenching medium. This observation is likely to be due to the fast cooling of the heated samples leading to the formation of the hardened structure. At high hardness values, the percentage elongation as well as the ductility of the samples will be low. This is in agreement with the elongation of the heated samples in the current study as shown in Figure 2.

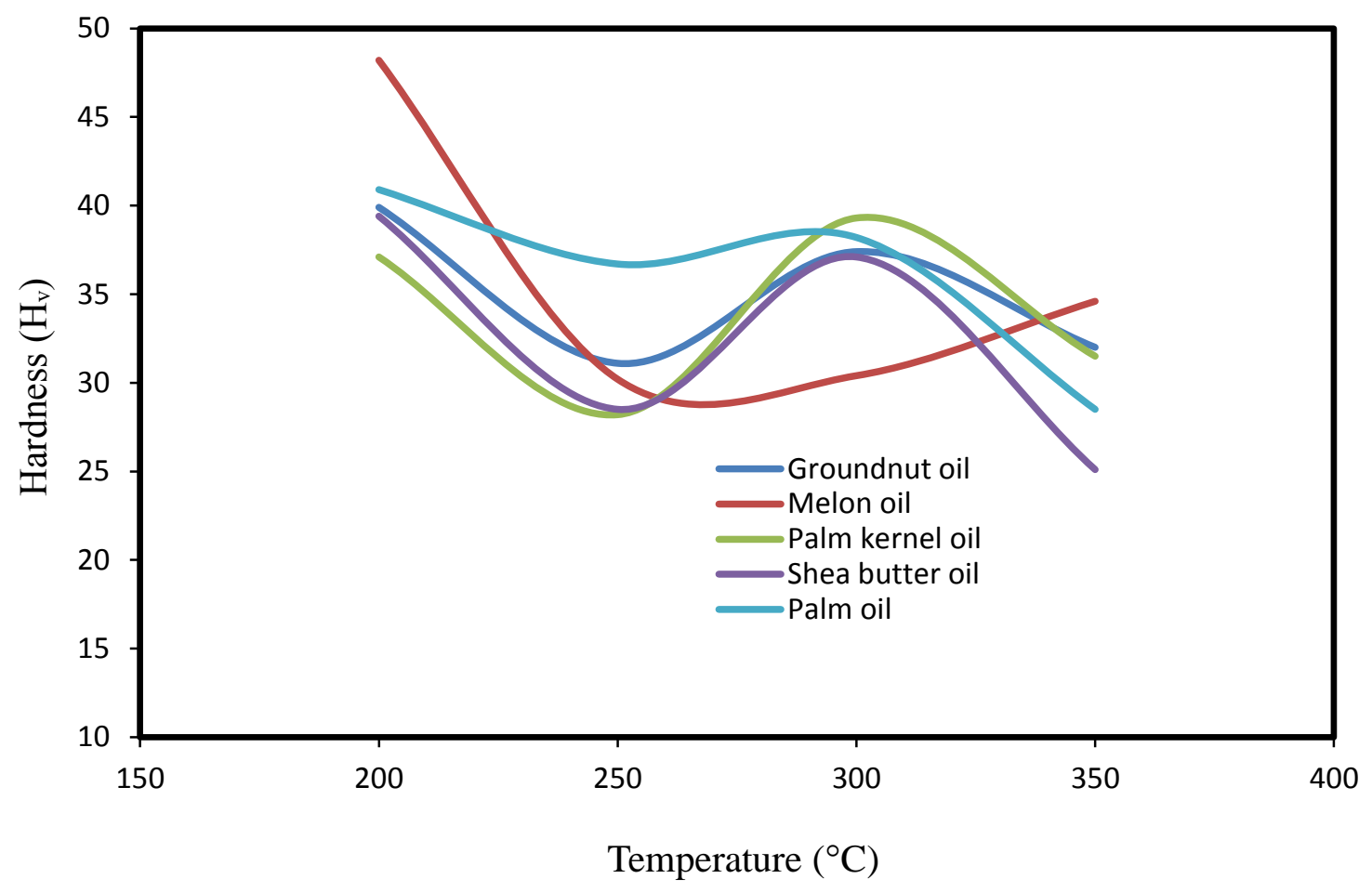

Figure 4. Vickers hardness of pure commercial aluminum in different bio-quenching oils at different heating temperatures.

\section{CONCLUSIONS}

i. The possibility of using some biodegradable oils for the solution hardening of pure commercial aluminum in order to improve its mechanical properties was established.

ii. Quenching with palm oil cools faster at $200^{\circ} \mathrm{C}$ and $250{ }^{\circ} \mathrm{C}$, while shea butter oil cools faster at $350^{\circ} \mathrm{C}$.

iii. It was evident that heat treatment with palm kernel oil offered the highest percentage elongation at $200{ }^{\circ} \mathrm{C}$, while shea butter oil was found to produce the highest percentage elongation at $350{ }^{\circ} \mathrm{C}$. 
iv. Shea butter oil also offered the best ductility at $200{ }^{\circ} \mathrm{C}$, while groundnut oil produced pure commercial aluminum with the best ductility after heat treatment at $300{ }^{\circ} \mathrm{C}$ and $350{ }^{\circ} \mathrm{C}$.

v. Groundnut oil can be used for quenching to improve the tensile strength at $350{ }^{\circ} \mathrm{C}$. The best bio-quenching oil in providing the highest hardness value for the aluminum sample was melon oil at heat treatment between $200{ }^{\circ} \mathrm{C}$ and $300^{\circ} \mathrm{C}$.

\section{ACKNOWLEDGEMENTS}

The authors would like to thank the technical staff of the Department of Mechanical Engineering for their support during the research.

\section{REFERENCES}

[1] Green JA. Aluminum recycling and processing for energy conservation and sustainability: ASM International; 2007.

[2] Krauss G. Steels: heat treatment and processing principles. ASM International, 1990. 1990:497.

[3] Feng C, Khan T. The effect of quenching medium on the wear behaviour of a Ti-6Al-4V alloy. J Mater Sci. 2008;43:788-92.

[4] Grishin SA, Churyukin YN. Evaluation of the cooling capacity of quenching media based on water. Met Sci Heat Treat. 1986;28:744-5.

[5] Tolstousov AV, Bannykh OA. New quenching media based on water-soluble polymers. Met Sci Heat Treat. 1981;23:104-6.

[6] Protsidim PS, Rudakova NY, Sheremeta BK. Regenerated oils as base of quenching media. Met Sci Heat Treat. 1988;30:86-8.

[7] Goryushin VV, Istomin NN, Ksenofontov AG, Marsel AV, Shevchenko SY. Quenching of ball-bearing steels and bearing parts in polymer medium UZSP-1. Met Sci Heat Treat. 1999;41:47-51.

[8] Adekunle A, Adebiyi K, Durowoju M. Impact of quench severity and hardness on aisi 4137 using eco-friendly quenchants as industrial heat treatment. Journal of Mechanical Engineering and Sciences. 2013;4:409-17.

[9] Odusote JK, Ajiboye TK, Rabiu AB. Evaluation of mechanical properties of medium carbon steel quenched in water and oil. Journal of Minerals and Materials Characterization and Engineering. 2012;11:859.

[10] Ndaliman M. An Assessment of Mechanical properties of medium carbon steel under different quenching media. Assumption University Journal of Technology. 2006;10:100-4.

[11] Adekunle A, Adebiyi K, Durowoju M. Performance evaluation of groundnut oil and melon oil as cutting fluids in machining operation. Acta Technica Corviniensis-Bulletin of Engineering. 2015;8:97.

[12] Xia Y, Larock RC. Vegetable oil-based polymeric materials: synthesis, properties, and applications. Green Chemistry. 2010;12:1893-909.

[13] GÜndÜz S, Çapar A. Influence of forging and cooling rate on microstructure and properties of medium carbon microalloy forging steel. Journal of Materials Science. 2006;41:561-4.

[14] Rajan T, Sharma C, Sharma A. Heat treatment: principles and techniques: PHI Learning Pvt. Ltd.; 2011. 